\title{
Roles of Myosin Va and Rab3D in Membrane Remodeling of Immature Secretory Granules
}

\author{
Tanja Kögel · Hans-Hermann Gerdes
}

Received: 14 June 2010/ Accepted: 2 September 2010/Published online: 16 November 2010

(C) The Author(s) 2010. This article is published with open access at Springerlink.com

\begin{abstract}
Neuroendocrine secretory granules (SGs) are formed at the trans-Golgi network (TGN) as immature intermediates. In PC12 cells, these immature SGs (ISGs) are transported within seconds to the cell cortex, where they move along actin filaments and complete maturation. This maturation process comprises acidification-dependent processing of cargo proteins, condensation of the SG matrix, and removal of membrane and proteins not destined to mature SGs (MSGs) into ISG-derived vesicles (IDVs). We investigated the roles of myosin Va and Rab3 isoforms in the maturation of ISGs in neuroendocrine PC12 cells. The expression of dominant-negative mutants of myosin $\mathrm{Va}$ or Rab3D blocked the removal of the endoprotease furin from ISGs. Furthermore, expression of mutant Rab3D, but not of mutant myosin Va, impaired cargo processing of SGs. In conclusion, our data suggest an implication of myosin Va and Rab3D in the maturation of SGs where they participate in overlapping but not identical tasks.
\end{abstract}

Keywords Dense core vesicle - Endocrine - Exocytosis . Furin - Hormone - Maturation · Myosin Va - Noc2 .

Processing $\cdot$ Rab3 $\cdot$ Rab27 $\cdot$ Secretory granule

\begin{tabular}{|c|c|}
\hline Abbre & \\
\hline BDM & Butanedione monoxime \\
\hline ISGs & Immature secretory granules \\
\hline
\end{tabular}

A commentary to this article can be found at doi: 10.1007/s10571-010-9610-0.

T. Kögel · H.-H. Gerdes $(\bowtie)$

Department of Biomedicine, University of Bergen,

Jonas Lies Vei 91, 5009 Bergen, Norway

e-mail: hans-hermann.gerdes@biomed.uib.no

$\begin{array}{ll}\text { IDVs } & \text { ISG-derived vesicles } \\ \text { MyoVa-tail } & \begin{array}{l}\text { Dominant-negative Myosin Va-tail fragment } \\ \text { Mature secretory granules }\end{array} \\ \text { MSGs } & \begin{array}{l}\text { Soluble } \quad N \text {-ethylmaleimide-sensitive-factor } \\ \text { attachment receptor }\end{array} \\ \text { SGs } & \begin{array}{l}\text { Secretory granules } \\ \text { trans-Golgi network }\end{array}\end{array}$

\section{Introduction}

In exocrine, endocrine, and neuroendocrine cells secretory granules (SGs) are synthesized at trans-Golgi network (TGN) as short-lived vesicular intermediates. These immature secretory granules (ISGs) are converted to mature SGs (MSGs), the storage organelle of hormones and neuropeptides. This involves a complex maturation process, which includes further refinement of the content and remodeling of the organelle membrane (Tooze et al. 2001). One of the beststudied paradigms in this context, the maturation of SGs in neuroendocrine PC12 cells, was shown to occur in several consecutive/concurrent steps, which partly depend on each other. First, newly formed ISGs undergo homotypic fusion (Urbe et al. 1998) in a syntaxin 6- and synaptotagmin IV-dependent manner (Wendler et al. 2001; Ahras et al. 2006). Second, the lumen of ISGs acidifies progressively and thereby promotes enzymatic processing of precursor proteins and condensation of luminal cargo (Gerdes et al. 1989; Urbe et al. 1997; Seidah et al. 2008). Third, proteins not destined for MSGs along with excess membrane are removed from maturing ISGs in clathrin-coated immature secretory granule-derived vesicles (IDVs) (Tooze 1998). The proteins shown to reside in ISGs but not in MSGs include furin (Dittie et al. 1997), mannose-6-phosphate 
receptor (M6PR), syntaxin 6, clathrin (Klumperman et al. 1998), carboxypeptidase D (Varlamov et al. 1999), synaptotagmin IV, VAMP4 (Eaton et al. 2000), and Golgi-associated, $\gamma$-ear-containing, ADP-ribosylation factor-binding protein (GGA) (Kakhlon et al. 2006).

Mature secretory granules (MSGs), the product of the maturation process, are subject of additional modification steps leading to their tethering, priming, and docking (Sorensen 2004). During these events, MSGs are segregated into different pools with specific release probabilities (Neher and Zucker 1993; Burgoyne and Morgan 2003; Rose et al. 2003; Sorensen 2004). Upon calciumdependent stimulation, the soluble $N$-ethylmaleimidesensitive-factor attachment receptor (SNARE) complex mediates the fusion of SGs with the plasma membrane (Burgoyne and Morgan 2003). This final step in the life cycle of SGs is orchestrated by numerous accessory/regulatory proteins (Burgoyne and Morgan 2003) in a celltype specific manner. These include munc13 and munc 18 (Shirakawa et al. 2004; Nili et al. 2006), Rab3 and Rab27 (Fukuda 2008), synaptotagmin-like proteins (Desnos et al. 2003; Fukuda 2005b) and myosin Va (Rose et al. 2003; Varadi et al. 2003; Ivarsson et al. 2005; Watanabe et al. 2005; Desnos et al. 2007; Kogel et al. 2010). For myosin $\mathrm{Va}$, two different roles in late trafficking steps have been proposed: transport of SGs along cortical actin fibers to the release sites (Rose et al. 2003) and docking of SGs at the cell cortex/plasma membrane (Watanabe et al. 2005; Desnos et al. 2007). Furthermore, recent studies on Rab3A and Rab27A suggest a role of both Rabs in the recruitment/tethering of SGs to the plasma membrane rather than in the priming and fusion step (Kasai et al. 2005; Tsuboi and Fukuda 2006). However, many open questions remain as to how these proteins control exocytosis of SGs. We have recently focused on potential functions of myosin $\mathrm{Va}$ and Rab 3 in early steps of SG trafficking and present evidence for an essential role of both proteins in SG maturation.

\section{Monitoring ISGs}

To analyze ISG maturation microscopically, we developed protocols to specifically label ISGs. This is necessary because only a small fraction of the entire SG population of neuroendocrine cells is immature due to their relatively short half-life (Tooze et al. 1991). We established a pulse-chase-like labeling of ISGs in PC12 cells, which was based on the expression of SG marker proteins tagged with green fluorescent protein. Importantly, we monitored the biosynthetic transport of these fusion proteins prior to their steady state distribution: transfected cells were incubated for $2 \mathrm{~h}$ at $37^{\circ} \mathrm{C}$, then for
$2 \mathrm{~h}$ at $20^{\circ} \mathrm{C}$ to accumulate fluorescent cargo in the transGolgi network (TGN) (pulse), followed by incubation at $37^{\circ} \mathrm{C}$ (chase) to allow budding of ISGs from the TGN (Kaether et al. 1997; Rudolf et al. 2001; Rudolf et al. 2003; Kogel et al. 2010). This permitted to monitor ISGs in an age- and thus maturation-dependent manner. The approach revealed unprecedented insights into the dynamics of ISGs in PC12 cells: (i) newly formed ISGs moved uni-directionally and in a microtubule-dependent manner to the cell periphery, (ii) ISGs were restricted to the F-actin rich cortex and underwent short directed movements while completing maturation such as the removal of furin (Rudolf et al. 2001, 2003), (iii) both the peripheral restriction and the movement of ISGs were found to be myosin Va-dependent, and (iv) the F-actindependent movement of ISGs decreased progressively during the $\sim 3-\mathrm{h}$ maturation period resulting in the immobilization of the major fraction of SGs (Rudolf et al. 2001). In agreement with this, we demonstrated by an in vitro binding assay that the fraction of fluorescent SGs, which detached from F-actin in an ATP-dependent manner, decreased progressively within the same time window (Kogel et al. 2010). Because the ATP-inhibited binding to F-actin in vitro could be mimicked by compromising myosin $\mathrm{Va}$, a selective inactivation of ISG-associated myosin Va during maturation is conceivable (Kogel et al. 2010).

\section{Role of Myosin Va in SG Maturation}

The concurrence of myosin Va-dependent transport and maturation of ISGs in the F-actin rich cortex (Rudolf et al. 2001, 2003) suggested that both events are closely linked. We therefore investigated a possible role of myosin $\mathrm{Va}$ in the membrane remodeling of maturing ISGs by analyzing the removal of the transmembrane protein furin as a paradigm. It is well documented that furin is contained in more than $80 \%$ of newly formed ISGs (Dittie et al. 1999) and is removed in clathrin-coated IDVs during ISG maturation (Dittie et al. 1997) (Fig. 1 left panel). When myosin Va was compromised by expression of a dominant-negative tail fragment of this motor protein or by siRNA silencing, the removal of furin was blocked (Fig. 1 right panel). Given that a similar interference with myosin $\mathrm{Vb}$ function did not impair the removal of furin, our data suggest an isoform-specific role of myosin $\mathrm{Va}$ in IDV formation (Kogel et al. 2010). Notably, under the same conditions, we did not find a dependence on myosin $\mathrm{Va}$ of luminal maturation processes such as $\mathrm{pH}$-dependent peptide processing or condensation of the matrix of SGs (Kogel et al. 2010). Taken together, our study provides compelling evidence for an important role of myosin $\mathrm{Va}$ in 


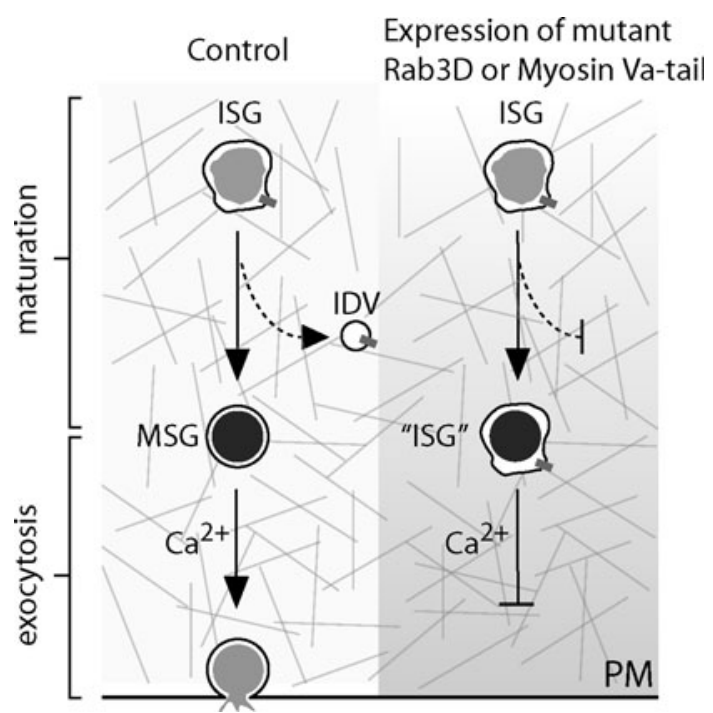

Fig. 1 Effects of dominant-negative myosin Va and Rab 3D on ISG maturation and exocytosis. The scheme illustrates ISG maturation and exocytosis in PC12 cells under controlled conditions (left) and under expression of dominant-negative myosin Va-tail or mutant Rab3D (right panel). Left panel in wild type cells furin (grey bar) exits (broken arrow) from ISGs in the F-actin (gray lines) rich cortex in ISG-derived vesicles (IDV, open circle). The resulting MSGs respond to exocytotic stimuli by fusion with the plasma membrane (PM, black line). Right panel upon expression of myosin Va-tail or mutant Rab3D, the exit of furin (grey bar) from ISGs is blocked (vertical black bar). The resulting SGs are not fully matured ("ISG") and do not exocytose upon stimulation (horizontal black bar)

membrane remodeling of ISGs, in addition to a role in transport and exocytosis. Apart from furin, the removal of other membrane proteins from ISGs may be affected upon compromising myosin $\mathrm{Va}$ and could have direct effects on the trafficking, subcellular distribution and exocytosis of SGs.

What could be the underlying mechanism of the myosin Va-dependent membrane remodeling? First, given that SGs in PC12 cells extensively cluster in the case of myosin Va-tail fragment expression (Rudolf et al. 2003), similar to organelles of other cell types (Wu et al. 1998), sterical hindrance could impede membrane remodeling. However, this is unlikely because the block of furin removal was also evident upon siRNA silencing, which does not lead to clustering of SGs (Rudolf et al. 2003; Kogel et al. 2010). Second, in the light of our finding that active myosin Va is associated with ISGs (Kogel et al. 2010), it is tempting to speculate that this motor protein exerts a mechanical force to promote budding of IDV, similar to the role that has been proposed for myosin VI in the biogenesis of plasma membrane-derived clathrin-coated vesicles (Buss et al. 2001). Third, it is conceivable that myosin Va exerts an indirect role in membrane remodeling of ISGs such as the transport of SGs to a specific site or binding of an essential factor.

\section{Role of Rab3D in SG Maturation}

Because myosin Va does not directly interact with membranes (Miller and Sheetz 2000), Rab proteins as central mediators of membrane traffic are likely candidates to cooperate with myosin $\mathrm{Va}$ in the membrane remodeling of ISGs. In a systematic screen of Rab family members in PC12 cells only seven Rab isoforms (Rab3A/B/C/D, $\mathrm{Rab} 27 \mathrm{~A} / \mathrm{B}$, and Rab37) were specifically targeted to densecore SGs (Fukuda 2008). Furthermore, intensive studies on Rab3 and Rab27 subfamily members clearly demonstrate an implication of both in regulated secretion, although the involvement of these proteins in specific steps of SG traffic remains unclear. In addition, recent observations indicate a role as sensor for the late maturation stages of SGs for Rab27 (Hannah et al. 2003; Merrins and Stuenkel 2008). Based on these data, we decided to analyze Rab3 isoforms as prime candidates for a potential role in SG maturation and found striking parallels to the role of myosin Va.

Because of our previous results indicating that ISGs complete their maturation in the F-actin rich cortex of PC12 cells, we first screened all four Rab3 isoforms and their nucleotide binding-deficient mutants for their potential interference with the cortical localization of ISGs. Transient expression of all constructs in PC12 cells, respectively, revealed a reduced cortical localization of SGs only in the case of the mutants of Rab3A and Rab3D. Subsequently, these two Rabs were analyzed for a potential role in membrane remodeling of maturing ISGs. Interestingly, only the expression of mutant Rab3D, but not of mutant Rab3A blocked the removal of furin (Fig. 1). Third, in contrast to myosin Va-tail expression, processing of the luminal SG protein secretogranin II was impeded upon expression of mutant Rab3D. The finding of clearly distinct functions of Rab3 isoforms on SG distribution and maturation was remarkable, because previous studies on the exocytosis of endocrine cells (Iezzi et al. 1999) and of mouse model neurons (Schluter et al. 2004) suggested that the four isoforms of Rab3 would play redundant roles.

Similar to Rab3D, the GGA3 clathrin adaptor protein and synaptotagmin IV were also found to be essential for both protein removal and prohormone processing. In the case of GGA3, its depletion not only led to a retention of syntaxin 6 and VAMP4 in MSGs but also to a decrease in activity of prohormone convertase 2 (Kakhlon et al. 2006). In the case of synaptotagmin IV, one of the SNAREs for homotypic SG fusion, this protein was shown to be necessary for cargo processing (Ahras et al. 2006). However, inhibition of ARF-1-recruitment to ISGs by brefeldin A blocked secretion from ISGs (Fernandez et al. 1997) and VAMP4 and synaptotagmin IV removal (Eaton et al. 2000), but not the processing of proopiomelanocortin (Fernandez et al. 1997). Thus, ARF-1 together with myosin 
Va (Kogel et al. 2010) represent examples of proteins executing a role in membrane remodeling of ISGs but not in cargo processing.

Our result of a specific role of Rab3D in SG maturation is in agreement with data obtained from several other studies. Indeed, Rab3D was found to associate with a population of SG with low buoyant density in parotid (Chan et al. 2000). Moreover, SGs of exocrine pancreas and parotid gland of Rab3D-knockout mice have an approximately doubled volume compared to wild-type littermates (Riedel et al. 2002). In addition, shrinkage of mouse zymogen granules at birth coincides with a first association of Rab3D with the zymogen granules (Ermak and Rothman 1983). Because these data indicate a role of Rab3D in determining the size of SGs, Riedel and colleagues speculated that Rab3D may restrict the homotypic fusion of ISGs (Riedel et al. 2002). However, we obtained in vitro evidence showing that neither wild type nor mutant Rab3D interfered with homotypic fusion of ISGs and thus argues against such a role of Rab3D. Instead, the demonstrated block of Rab3D mutant on furin removal suggests that the increased size of SGs in Rab 3D knockout mice could result from insufficient membrane removal during ISG maturation.

\section{Cooperativity of Myosin Va and Rab3D?}

Because interference with either myosin Va or Rab3D function similarly impaired the removal of furin from ISGs (Table 1), both proteins may cooperate to accomplish membrane remodeling. This idea is consistent with our observation that both myosin $\mathrm{Va}$ and Rab3D were detected on ISGs already 12 min after biogenesis at the TGN. Further support for a cooperative model is provided by the finding that the application of the myosin inhibitor butanedione monoxime (BDM) increased the number of Rab3D positive lamellar bodies, the secretory organelles of alveolar epithelial type II cells (van Weeren et al. 2004). Interestingly, the authors describe small Rab3D positive vesicles in the proximity to the lamellar bodies (van Weeren et al. 2004), which might be the equivalent

Table 1 Role of myosin Va and Rab3D in the life cycle of SGs

\begin{tabular}{lll}
\hline & Myosin Va & Rab3D \\
\hline $\begin{array}{l}\text { Cortical } \\
\text { restriction }\end{array}$ & Kogel et al. 2010) & \\
Furin removal & $(+)$ (Kogel et al. 2010) & $(+)$ (data not shown) \\
Processing of SgII & $(-)$ (Kogel et al. 2010) & $(+)$ (data not shown) \\
Exocytosis & $(+)$ (Kogel et al. 2010) & $(+)$ (Baldini et al. 1998) \\
\hline
\end{tabular}

to the IDVs of neuroendocrine cells (Tooze 1998). These data suggest that myosin function is necessary for releasing Rab3D from the respective secretory organelles. Furthermore, Rab3D positive subpopulations of exocrine vesicles of two different cell types do not exocytose upon stimulation (Valentijn et al. 2000; van Weeren et al. 2004). Instead, these vesicles become coated with F-actin and subsequently lose Rab3D (Valentijn et al. 2000; van Weeren et al. 2004). This suggests a transient role for Rab3D on SGs, which involves F-actin and takes place before the achievement of exocytosis competence in exocrine cells.

In analogy to melanosomes where myosin $\mathrm{Va}$ is bound via melanophilin and Rab27 (Hammer and Wu 2002; Fukuda 2008), it is conceivable that synaptotagmin-like effector proteins mediate the putative interaction of myosin $\mathrm{Va}$ and Rab3D (Fig. 2). Neuroendocrine cells express several such effectors including granuphilin, Noc2, MyRIP, rabphilin, and RIM2 (Fukuda et al. 2002, 2004; Fukuda 2003a, b, 2004, 2005a; Desnos et al. 2003; Waselle et al. 2003). While granuphilin, MyRIP, rabphilin, and RIM2 have been implicated in the final exocytosis step, several lines of evidence indicate Noc2 as a promising candidate to regulate an earlier step in SG trafficking, i.e., to link myosin Va to ISG-associated Rab3D (Fig. 2). One line of support was obtained from $N o c 2^{-1-}$ mice, where exocrine cells contained SGs of abnormally large size and irregular shape (Shibasaki and Seino 2005). This observation is reminiscent of studies on Rab3D-knockout mice, in which an increase in granular size in some exocrine cell

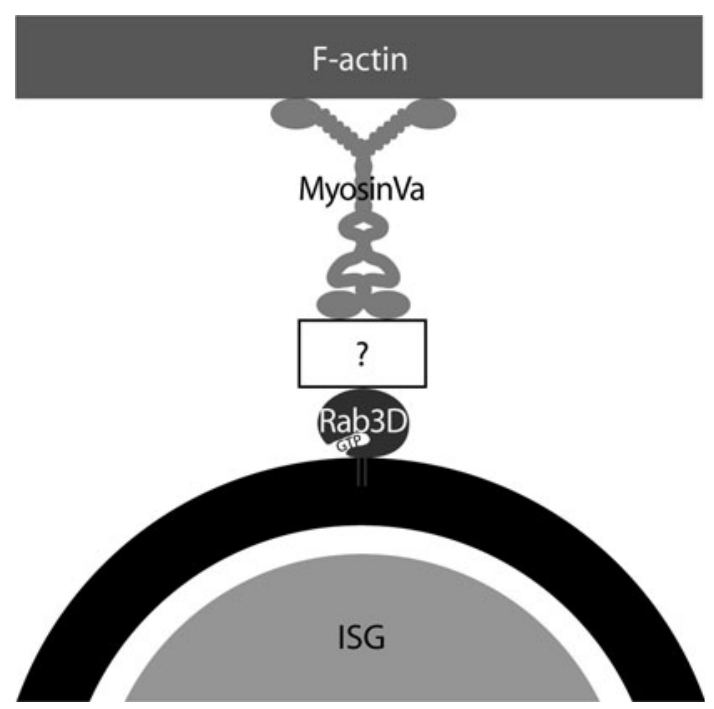

Fig. 2 Model proposing the interaction of ISGs with F-actin. The scheme illustrates the putative anchorage of myosin Va to ISGs. Rab3D associates with the ISG membrane in the GTP-bound form and recruits the F-actin-dependent motor protein myosin Va through a not yet identified effector protein (white box with “?”) 
types was reported (Riedel et al. 2002). Furthermore, in $N o 2^{-I-}$ mice the regulated release of insulin secreting cells was shown to be impaired. Although these mice displayed normal glucose levels, the amount of insulin released under stress conditions was inappropriate and the mice became hyperglycemic (Matsumoto et al. 2004). These symptoms might be the result of impaired proinsulin processing, reminiscent of our data on the effect of compromised Rab3D on cargo processing in PC12 cells. Hence, it will be interesting to investigate whether Noc2 functions in SG maturation in concert with Rab3D and myosin Va.

In general, the composition of complexes comprising Rab proteins, effectors, and myosin Va bound to SGs may change in a temporal fashion to regulate the sequential steps of SG biogenesis and trafficking, allowing elaborate fine-tuning of exocytosis in response to physiological conditions. In agreement with this hypothesis, many of the Rab and myosin binding proteins were shown to be embedded into higher regulatory networks involving protein kinase A/cAMP (Schluter et al. 1999; Kashima et al. 2001; Abderrahmani et al. 2006; Goehring et al. 2007), calcium-CaM-dependent kinase II (Schluter et al. 1999), micro RNA repressors, and transcription factors (Plaisance et al. 2006). Most relevant in light of our study is the recently demonstrated role of the transcriptional factor MIST1 in the down-regulation of Rab3D and in regulating exocrine granule maturation (Tian et al. 2010).

Acknowledgment We thank Rüdiger Rudolf for comments on the manuscript.

Open Access This article is distributed under the terms of the Creative Commons Attribution Noncommercial License which permits any noncommercial use, distribution, and reproduction in any medium, provided the original author(s) and source are credited.

\section{References}

Abderrahmani A, Cheviet S, Ferdaoussi M, Coppola T, Waeber G, Regazzi R (2006) ICER induced by hyperglycemia represses the expression of genes essential for insulin exocytosis. EMBO J 25:977-986

Ahras M, Otto GP, Tooze SA (2006) Synaptotagmin IV is necessary for the maturation of secretory granules in PC12 cells. J Cell Biol 173:241-251

Baldini G, Wang G, Weber M, Zweyer M, Bareggi R, Witkin JW, Martelli AM (1998) Expression of Rab3D N135I inhibits regulated secretion of ACTH in AtT-20 cells. J Cell Biol 140: 305-313

Burgoyne RD, Morgan A (2003) Secretory granule exocytosis. Physiol Rev 83:581-632

Buss F, Arden SD, Lindsay M, Luzio JP, Kendrick-Jones J (2001) Myosin VI isoform localized to clathrin-coated vesicles with a role in clathrin-mediated endocytosis. EMBO J 20:3676-3684

Chan D, Lin J, Raffaniello RD (2000) Expression and localization of rab escort protein isoforms in parotid acinar cells from rat. J Cell Physiol 185:339-347
Desnos C, Schonn JS, Huet S, Tran VS, El-Amraoui A, Raposo G, Fanget I, Chapuis C, Menasche G, de Saint Basile G, Petit C, Cribier S, Henry JP, Darchen F (2003) Rab27A and its effector MyRIP link secretory granules to F-actin and control their motion towards release sites. J Cell Biol 163:559-570

Desnos C, Huet S, Fanget I, Chapuis C, Bottiger C, Racine V, Sibarita JB, Henry JP, Darchen F (2007) Myosin va mediates docking of secretory granules at the plasma membrane. J Neurosci 27:10636-10645

Dittie AS, Thomas L, Thomas G, Tooze SA (1997) Furin is sorted into the regulated secretory pathway in neuroendocrine cells, interacts with the AP-1 complex, and is removed during granule maturation by a casein kinase II dependent mechanism. EMBO J $16: 4859-4870$

Dittie AS, Klumperman J, Tooze SA (1999) Differential distribution of mannose-6-phosphate receptors and furin in immature secretory granules. J Cell Sci 112:3955-3966

Eaton BA, Haugwitz M, Lau D, Moore HP (2000) Biogenesis of regulated exocytotic carriers in neuroendocrine cells. J Neurosci 20:7334-7344

Ermak TH, Rothman SS (1983) Increase in zymogen granule volume accounts for increase in volume density during prenatal development of pancreas. Anat Rec 207:487-501

Fernandez CJ, Haugwitz M, Eaton B, Moore HP (1997) Distinct molecular events during secretory granule biogenesis revealed by sensitivities to brefeldin A. Mol Biol Cell 8:2171-2185

Fukuda M (2003a) Distinct Rab binding specificity of Rim1, Rim2, rabphilin, and Noc2. Identification of a critical determinant of Rab3A/ Rab27A recognition by Rim2. J Biol Chem 278:15373-15380

Fukuda M (2003b) Slp4-a/granuphilin-a inhibits dense-core vesicle exocytosis through interaction with the GDP-bound form of Rab27A in PC12 cells. J Biol Chem 278:15390-15396

Fukuda M (2004) Alternative splicing in the first alpha-helical region of the Rab-binding domain of Rim regulates Rab3A binding activity: is Rim a Rab3 effector protein during evolution? Genes Cells 9:831-842

Fukuda M (2005a) Assay and functional interactions of Rim2 with Rab3. Methods Enzymol 403:457-468

Fukuda M (2005b) Versatile role of Rab27 in membrane trafficking: focus on the Rab27 effector families. J Biochem (Tokyo) 137:9-16

Fukuda M (2008) Regulation of secretory vesicle traffic by Rab small GTPases. Cell Mol Life Sci 65:2801-2813

Fukuda M, Kanno E, Saegusa C, Ogata Y, Kuroda TS (2002) Slp4-a/ granuphilin-a regulates dense-core vesicle exocytosis in PC12 cells. J Biol Chem 277:39673-39678

Fukuda M, Kanno E, Yamamoto A (2004) Rabphilin and Noc2 are recruited to dense-core vesicles through specific interaction with Rab27A in PC12 cells. J Biol Chem 279:13065-13075

Gerdes HH, Rosa P, Phillips E, Baeuerle PA, Frank R, Argos P, Huttner WB (1989) The primary structure of human secretogranin II, a widespread tyrosine-sulfated secretory granule protein that exhibits low $\mathrm{pH}-$ and calcium-induced aggregation. J Biol Chem 264:12009-12015

Goehring AS, Pedroja BS, Hinke SA, Langeberg LK, Scott JD (2007) MyRIP anchors protein kinase A to the exocyst complex. J Biol Chem 282:33155-33167

Hammer JA 3rd, Wu XS (2002) Rabs grab motors: defining the connections between Rab GTPases and motor proteins. Curr Opin Cell Biol 14:69-75

Hannah MJ, Hume AN, Arribas M, Williams R, Hewlett LJ, Seabra MC, Cutler DF (2003) Weibel-Palade bodies recruit Rab27 by a content-driven, maturation-dependent mechanism that is independent of cell type. J Cell Sci 116:3939-3948

Iezzi M, Escher G, Meda P, Charollais A, Baldini G, Darchen F, Wollheim CB, Regazzi R (1999) Subcellular distribution and function of Rab3A, B, C, and D isoforms in insulin-secreting cells. Mol Endocrinol 13:202-212 
Ivarsson R, Jing X, Waselle L, Regazzi R, Renstrom E (2005) Myosin $5 \mathrm{a}$ controls insulin granule recruitment during late-phase secretion. Traffic 6:1027-1035

Kaether C, Salm T, Glombik M, Almers W, Gerdes H-H (1997) Targeting of green fluorescent protein to neuroendocrine secretory granules: a new tool for real time studies of regulated protein secretion. Eur J Cell Biol 74:133-142

Kakhlon O, Sakya P, Larijani B, Watson R, Tooze SA (2006) GGA function is required for maturation of neuroendocrine secretory granules. EMBO J 25:1590-1602

Kasai K, Ohara-Imaizumi M, Takahashi N, Mizutani S, Zhao S, Kikuta T, Kasai H, Nagamatsu S, Gomi H, Izumi T (2005) Rab27a mediates the tight docking of insulin granules onto the plasma membrane during glucose stimulation. J Clin Invest 115:388-396

Kashima Y, Miki T, Shibasaki T, Ozaki N, Miyazaki M, Yano H, Seino S (2001) Critical role of cAMP-GEFII-Rim2 complex in incretinpotentiated insulin secretion. J Biol Chem 276:46046-46053

Klumperman J, Kuliawat R, Griffith JM, Geuze HJ, Arvan P (1998) Mannose 6-phosphate receptors are sorted from immature secretory granules via adaptor protein AP-1, clathrin, and syntaxin 6-positive vesicles. J Cell Biol 141:359-371

Kogel T, Rudolf R, Hodneland E, Hellwig A, Kuznetsov SA, Seiler F, Sollner TH, Barroso J, Gerdes HH (2010) Distinct roles of myosin $\mathrm{Va}$ in membrane remodeling and exocytosis of secretory granules. Traffic 11:637-650

Matsumoto M, Miki T, Shibasaki T, Kawaguchi M, Shinozaki H, Nio J, Saraya A, Koseki H, Miyazaki M, Iwanaga T, Seino S (2004) Noc2 is essential in normal regulation of exocytosis in endocrine and exocrine cells. Proc Natl Acad Sci USA 101:8313-8318

Merrins MJ, Stuenkel EL (2008) Kinetics of Rab27a-dependent actions on vesicle docking and priming in pancreatic beta-cells. J Physiol 586:5367-5381

Miller KE, Sheetz MP (2000) Characterization of myosin V binding to brain vesicles. J Biol Chem 275:2598-2606

Neher E, Zucker RS (1993) Multiple calcium-dependent processes related to secretion in bovine chromaffin cells. Neuron 10:21-30

Nili U, de Wit H, Gulyas-Kovacs A, Toonen RF, Sorensen JB, Verhage M, Ashery U (2006) Munc18-1 phosphorylation by protein kinase $C$ potentiates vesicle pool replenishment in bovine chromaffin cells. Neuroscience 143:487-500

Plaisance V, Abderrahmani A, Perret-Menoud V, Jacquemin P, Lemaigre F, Regazzi R (2006) MicroRNA-9 controls the expression of Granuphilin/Slp4 and the secretory response of insulin-producing cells. J Biol Chem 281:26932-26942

Riedel D, Antonin W, Fernandez-Chacon R, Alvarez de Toledo G, Jo T, Geppert M, Valentijn JA, Valentijn K, Jamieson JD, Sudhof TC, Jahn R (2002) RaB3D is not required for exocrine exocytosis but for maintenance of normally sized secretory granules. Mol Cell Biol 22:6487-6497

Rose SD, Lejen T, Casaletti L, Larson RE, Pene TD, Trifaro JM (2003) Myosins II and V in chromaffin cells: myosin V is a chromaffin vesicle molecular motor involved in secretion. J Neurochem 85:287-298

Rudolf R, Salm T, Rustom A, Gerdes H-H (2001) Dynamics of immature secretory granules: role of cytoskeletal elements during transport, cortical restriction and F-actin-dependent tethering. Mol Biol Cell 12:1353-1365

Rudolf R, Kogel T, Kuznetsov SA, Salm T, Schlicker O, Hellwig A, Hammer JA 3rd, Gerdes HH (2003) Myosin Va facilitates the distribution of secretory granules in the F-actin rich cortex of PC12 cells. J Cell Sci 116:1339-1348

Schluter OM, Schnell E, Verhage M, Tzonopoulos T, Nicoll RA, Janz R, Malenka RC, Geppert M, Sudhof TC (1999) Rabphilin knockout mice reveal that rabphilin is not required for Rab3 function in regulating neurotransmitter release. J Neurosci 19:5834-5846
Schluter OM, Schmitz F, Jahn R, Rosenmund C, Sudhof TC (2004) A complete genetic analysis of neuronal Rab3 function. J Neurosci 24:6629-6637

Seidah NG, Mayer G, Zaid A, Rousselet E, Nassoury N, Poirier S, Essalmani R, Prat A (2008) The activation and physiological functions of the proprotein convertases. Int J Biochem Cell Biol 40:1111-1125

Shibasaki T, Seino S (2005) Physical and functional interaction of noc2/rab3 in exocytosis. Methods Enzymol 403:408-419

Shirakawa R, Higashi T, Tabuchi A, Yoshioka A, Nishioka H, Fukuda M, Kita T, Horiuchi H (2004) Munc13-4 is a GTP-Rab27binding protein regulating dense core granule secretion in platelets. J Biol Chem 279:10730-10737

Sorensen JB (2004) Formation, stabilisation and fusion of the readily releasable pool of secretory vesicles. Pflugers Arch 448:347-362

Tian X, Jin RU, Bredemeyer AJ, Oates EJ, Blazewska KM, McKenna CE, Mills JC (2010) RAB26 and RAB3D are direct transcriptional targets of MIST1 that regulate exocrine granule maturation. Mol Cell Biol 30:1269-1284

Tooze SA (1998) Biogenesis of secretory granules in the trans-Golgi network of neuroendocrine and endocrine cells. Biochim Biophys Acta 1404:231-244

Tooze SA, Flatmark T, Tooze J, Huttner WB (1991) Characterization of the immature secretory granule, an intermediate in granule biogenesis. J Cell Biol 115:1491-1503

Tooze SA, Martens GJ, Huttner WB (2001) Secretory granule biogenesis: rafting to the SNARE. Trends Cell Biol 11:116-122

Tsuboi T, Fukuda M (2006) Rab3A and Rab27A cooperatively regulate the docking step of dense-core vesicle exocytosis in PC12 cells. J Cell Sci 119:2196-2203

Urbe S, Dittie AS, Tooze SA (1997) pH-dependent processing of secretogranin II by the endopeptidase PC2 in isolated immature secretory granules. Biochem J 321:65-74

Urbe S, Page LJ, Tooze SA (1998) Homotypic fusion of immature secretory granules during maturation in a cell-free assay. J Cell Biol 143:1831-1844

Valentijn JA, Valentijn K, Pastore LM, Jamieson JD (2000) Actin coating of secretory granules during regulated exocytosis correlates with the release of rab3D. Proc Natl Acad Sci USA 97:1091-1095

van Weeren L, de Graaff AM, Jamieson JD, Batenburg JJ, Valentijn JA (2004) Rab3D and actin reveal distinct lamellar body subpopulations in alveolar epithelial type II cells. Am J Respir Cell Mol Biol 30:288-295

Varadi A, Tsuboi T, Johnson-Cadwell LI, Allan VJ, Rutter GA (2003) Kinesin I and cytoplasmic dynein orchestrate glucose-stimulated insulin-containing vesicle movements in clonal MIN6 beta-cells. Biochem Biophys Res Commun 311:272-282

Varlamov O, Eng FJ, Novikova EG, Fricker LD (1999) Localization of metallocarboxypeptidase D in AtT-20 cells. Potential role in prohormone processing. J Biol Chem 274:14759-14767

Waselle L, Coppola T, Fukuda M, Iezzi M, El-Amraoui A, Petit C, Regazzi R (2003) Involvement of the Rab27 binding protein Slac2c/MyRIP in insulin exocytosis. Mol Biol Cell 14:4103-4113

Watanabe M, Nomura K, Ohyama A, Ishikawa R, Komiya Y, Hosaka K, Yamauchi E, Taniguchi H, Sasakawa N, Kumakura K, Ushiki T, Sato O, Ikebe M, Igarashi M (2005) Myosin-Va regulates exocytosis through the submicromolar $\mathrm{Ca}^{2+}$-dependent binding of syntaxin-1A. Mol Biol Cell 16:4519-4530

Wendler F, Page L, Urbe S, Tooze SA (2001) Homotypic fusion of immature secretory granules during maturation requires syntaxin 6. Mol Biol Cell 12:1699-1709

Wu X, Bowers B, Rao K, Wei Q, Hammer JA 3rd (1998) Visualization of melanosome dynamics within wild-type and dilute melanocytes suggests a paradigm for myosin $\mathrm{V}$ function in vivo. J Cell Biol 143:1899-1918 